\title{
Listeria rocourtiae sp. nov.
}

\author{
Alexandre Leclercq, ${ }^{1}$ Dominique Clermont, $^{2}$ Chantal Bizet, $^{2}$ \\ Patrick A. D. Grimont, ${ }^{3}$ Anne Le Flèche-Matéos, ${ }^{3}$ Sylvie M. Roche, ${ }^{4}$ \\ Carmen Buchrieser, ${ }^{5}$ Véronique Cadet-Daniel, ${ }^{1}$ Alban Le Monnier, ${ }^{1}$ \\ Marc Lecuit ${ }^{1,6}$ and Franz Allerberger ${ }^{7}$
}

Correspondence

Alexandre Leclercq alexlec@pasteur.fr

\author{
${ }^{1}$ Institut Pasteur, Groupe Microorganismes et barrières de l'hôte, WHO Collaborating Center for \\ Foodborne Listeriosis and French National Reference Center for Listeria, Paris, France \\ ${ }^{2}$ Institut Pasteur, Collection de l'Institut Pasteur (CIP), Paris, France \\ ${ }^{3}$ Institut Pasteur, Unité Biodiversité des Bactéries Pathogènes Emergentes, Paris, France \\ ${ }^{4}$ Institut National de Recherche Agronomique, Infectiologie Animale et Santé Publique Tours, \\ UR1282 Nouzilly, France \\ ${ }^{5}$ Institut Pasteur, Biologie des bactéries Intracellulaires and CNRS URA 2171, Paris, France \\ ${ }^{6}$ Université Paris Descartes, Department of Infectious Diseases and Tropical Medicine, \\ Necker-Pasteur Center for Infectious Diseases, Hôpital Necker-Enfants Malades, \\ Assistance Publique-Hôpitaux de Paris, F-75015 Paris, France \\ ${ }^{7}$ Österreichische Agentur für Gesundheit und Ernährungssicherheit (AGES), Wien, Austria
}

Molecular methods have deeply modified our vision of the taxonomic structure of the genus Listeria (Rocourt et al., 1982; Seeliger \& Jones, 1986). At the time of writing, the genus Listeria is composed of six species: L. monocytogenes, L. innocua, L. welshimeri, L. seeligeri, $L$. grayi and $L$. ivanovii, the latter comprising $L$. ivanovii subsp. ivanovii and $L$. ivanovii subsp. londoniensis (Rocourt \& Buchrieser, 2007). Although species of the genus Listeria are environmental bacteria, two species (L. monocytogenes and L. ivanovii) are pathogenic for animals and humans. L. monocytogenes is the most commonly isolated member responsible for listeriosis in humans and animals.

The purposes of this work were to (i) characterize an isolate resembling members of the genus Listeria but not

Abbreviations: PIPLC, phosphatidylinositol-specific phospholipase C.

The GenBank/EMBL/DDBJ accession number for the rrs gene sequence of strain $\mathrm{CIP} 109804^{\top}$ is $\mathrm{FJ} 557241$.

A dendrogram of hierarchical clustering reconstructed with the $\mathrm{J}$ Express program based on the presence and the absence of genes, and a table detailing the origins and descriptions of reference strains used in the comparative genomic DNA array hybridization and analysis are available with the online version of this paper. identified as belonging to any known species, (ii) position the isolate in the bacterial phylogenetic tree, and (iii) describe the isolate as representing a novel species for which the name Listeria rocourtiae sp. nov. is proposed.

Strain CIP $109804^{\mathrm{T}}$ was recovered from a single sample of pre-cut lettuce at the Federal Food Safety Microbiology Laboratory in Salzburg (Austria) in 2002. This sample was detected positive for the presence of Listeria monocytogenes by the enzyme-linked fluorescence assay Vidas Listeria monocytogenes II (bioMérieux). The strain was isolated on RAPID' L.mono (Bio-Rad), an agar medium based on the chromogenic detection of phosphatidylinositol-specific phospholipase C (PIPLC) and xylose fermentation (Leclercq, 2004). Multiple colonies with identical phenotypic characteristics according to the RAPID' L.mono manufacturer's instructions for positive confirmation were obtained and incorrectly identified as L. monocytogenes. No other known species of the genus Listeria was detected. One isolate was then sent to the National Reference Laboratory (NRL) of Austria for Listeria monocytogenes for confirmation of its identification. This isolate was not confirmed as L. monocytogenes by NRL but as a potential new species and 
was sent to the WHO Collaborating Centre for Foodborne Listeriosis for its characterization.

In order to characterize the isolate, the following phenotypic and genotypic methods were undertaken. Colonies were observed on ALOA (AES laboratoire), a medium based on the simultaneous detection of PIPLC and $\beta$-glucosidase activities. Gram staining, respiratory characteristics, catalase and oxidase production and the presence of a capsule by the use of a wet Indian ink film were determined. Motility was tested by stab-inoculating mannitol-mobility semi-solid agar (Bio$\mathrm{Rad}$ ) and semi-solid nutrient agar containing $0.4 \%$ agar in a U-shaped tube. Haemolysis was determined on Columbia agar containing $5 \%$ defibrinated horse blood (Oxoid). Furthermore, the CAMP test (Christie et al., 1944) was performed on Columbia agar containing $5 \%$ defibrinated sheep blood (Oxoid) using Staphylococcus aureus CIP 5710 and Rhodococcus equi NCTC 1621. Growth at different temperatures was determined in trypto-casein-soy broth and agar (Difco) after incubation at $4{ }^{\circ} \mathrm{C}$ for 10 days and at 22,30 , 37 and $42{ }^{\circ} \mathrm{C}$ for 7 days. Acid production from carbohydrates was determined by using the API50CH system (bioMérieux) as recommended by the manufacturer. Reactions were recorded after 2, 5, 10 and 15 days of incubation at $30{ }^{\circ} \mathrm{C}$. Biochemical tests were completed with API-Listeria strips (bioMérieux) as recommended by the manufacturer (Bille et al., 1992). Serotyping of strain CIP $109804^{\mathrm{T}}$ was performed as described by Seeliger \& Höhne (1979).

The rrs gene (encoding 16S rRNA) was amplified by PCR using the universal primers A, 5'-AGAGTTTGATCATGGCTCAG-3' (position 8-27, Escherichia coli numbering system), and $\mathrm{H}, 5^{\prime}$-AAGGAGGTGATCCAACCGCA-3' (1541-1522) (Böttger, 1989), in a GeneAmp thermal cycler (Perkin-Elmer) with the following cycle parameters: $4 \mathrm{~min}$ at $94{ }^{\circ} \mathrm{C} ; 25$ cycles of $1 \mathrm{~min}$ at $94{ }^{\circ} \mathrm{C}, 1 \mathrm{~min}$ at $57^{\circ} \mathrm{C}$ and 2 min at $72{ }^{\circ} \mathrm{C}$; final extension step at $72{ }^{\circ} \mathrm{C}$ for $5 \mathrm{~min}$. Each PCR product was purified by filtration on $\mathrm{P} 100 \mathrm{Gel}$ Fine (Bio-Rad) and then sequenced by using primers $\mathrm{A}, \mathrm{H}$ and eight other sequencing primers $(E$. coli numbering system): B, 5'-CTCCTACGGGAGGCAGCAGT-3' (339358); C, $5^{\prime}$-ACTGCTGCCTCCCGTAGGAG-3' (358-339); D, 5'-CGTGCCAGCAGCCGCGGTAAT-3' (514-534); E, 5'-TTACCGCGGCTGCTGGCACGT-3' (533-514); F, 5' GATTAGATACCCTGGTAG-3' (786-803); G, 5' -GCATGTGGTTTAATTCGA-3' (947-964); I, 5' -TCGAATTAAACCACATGC-3' (964-947) and J, 5'-AGGGTTGCGCTCGTTGCGG-3' (1115-1097) with the ABI PRISM BigDye terminator cycle sequencing kit and the ABI PRISM 3700 DNA sequencer according to the manufacturer's instructions (Applied Biosystems). The almost-complete rrs gene sequence for CIP $109804^{\mathrm{T}}$ (1539 nt; GenBank accession FJ557241) was obtained by using the Script Assembler Tool Kit developed by Eric Deveaud and Betina Setterblad, Groupe Logiciels et Banques de Données, Institut Pasteur (unpublished program).

Phylogenetic analysis based on the rrs gene sequence of strain CIP $109804^{\mathrm{T}}$ and reference type strains belonging to the genus Listeria retrieved from GenBank was performed. Sequences were aligned by using CLUSTAL x (Thompson et al., 1997) and Jukes-Cantor evolutionary distances were calculated (Jukes \& Cantor, 1969). A neighbour-joining (Saitou \& Nei, 1987) phylogenetic tree was reconstructed by using the Taxotron software (P. Grimont, Paris, France).

A specific PCR analysis, allowing separation of the four major serotypes $(1 / 2 \mathrm{a}, 1 / 2 \mathrm{~b}, 1 / 2 \mathrm{c}$ and $4 \mathrm{~b})$ of $L$. monocytogenes into four distinct PCR groups was performed as described by Doumith et al. (2004a).

A Listeria biodiversity DNA array (Doumith et al., 2004b; Hong et al., 2007; Volokhov et al., 2007) was used to detect the presence of known L. monocytogenes genes, including those involved in virulence. The binary data obtained from 710 probes were analysed by hierarchical clustering using the program J-Express (Dysvik \& Jonassen, 2001).

Virulence tests commonly used for species of the genus Listeria were undertaken as described by Roche et al. (2001). These included the plaque-forming assay on confluent human adenocarcinoma HT-29 cell monolayers (ECACC no. 85061109) (Fogh \& Trempe, 1975; Roche et al., 2001) and an in vivo test after subcutaneous inoculation into the left footpad of conventional Swiss mice (Charles River, L'Arbresle, France) (Audurier et al., 1981). HT-29 cell monolayers were infected with 2 to $7 \log$ Listeria per well for $2 \mathrm{~h}$ at $37{ }^{\circ} \mathrm{C}$. Conventional Swiss mice were inoculated with $4 \log$ c.f.u. Listeria in $50 \mu \mathrm{l}$ for subcutaneous injection. The L. monocytogenes strain EGDe (BUG 1600) was used as a positive control, the L. innocua strain BUG 499 as a negative one.

Finally, susceptibility to a wide range of antibacterial agents was determined with the disk diffusion method on MuellerHinton agar plates (Bio-Rad) and minimal inhibitory concentrations were determined for the antibiotics that are clinically relevant for listeriosis. Susceptibility to $\beta$ lactams and trimethoprim was also tested by the E-test procedure ( $\mathrm{AB}$ Biodisk), according to the guidelines of the Antibiogram Committee of the French Society for Microbiology (CA-SFM) (Anonymous, 2006). The natural susceptibility to antibiotics of strain CIP $109804^{\mathrm{T}}$ was deduced by using the database on natural susceptibility of Listeria species (Troxler et al., 2000). Moreover, we used the interpretative criteria and recommendations from the CASFM (freely available at http://www.sfm.asso.fr) and the European Committee on Antibiotic Susceptibility Testing (EUCAST, freely available at http://www.escmid.org/ research_projects/eu_cast/) for the interpretation of the in vitro susceptibility of $L$. monocytogenes to antibiotics.

The results of these different tests showed that the food isolate (CIP $109804^{\mathrm{T}}$ ) was a Gram-stain-positive, non-sporeforming, non-capsulated, rod-shaped bacterium that was non-motile at $37^{\circ} \mathrm{C}$. At 4,22 and $30^{\circ} \mathrm{C}$, the isolate swarmed through semisolid medium in a U-shaped tube and showed a typical 'umbrella' motility in tubes of mannitol-mobility semi-solid agar. Colonies on trypto-casein-soy agar plates 
had a diameter of 0.5 to $1.0 \mathrm{~mm}$ after $48 \mathrm{~h}$ of growth at $30{ }^{\circ} \mathrm{C}$. They were round, translucent with dew-drop appearance and low convex with a finely textured surface and entire margin. Colonies appeared blue-green when viewed under a magnifying glass with oblique transmitted light, and bluish grey by normal illumination. The strain showed an optimal growth temperature of $30^{\circ} \mathrm{C}$. This strain did not grow at $42{ }^{\circ} \mathrm{C}$ and was able to grow at $4{ }^{\circ} \mathrm{C}$ (only in trypto-casein-soy broth and in mannitol-mobility semi-solid agar) within $48 \mathrm{~h}$. It was facultatively anaerobic, catalase-positive, nitrate reductase-positive, mannitol-positive and oxidase-negative. It was non-haemolytic and gave negative results for the CAMP test. Thus, this isolate (CIP 109804 ${ }^{\mathrm{T}}$ ) could be readily distinguished from the other species of the genus Listeria according to the results of the biochemical tests shown in Table 1. The API-Listeria strips showed negative results for arylamidase, D-arabitol, glucose-1-phosphate and D-tagatose, and positive results for aesculin hydrolysis, $\alpha$-mannosidase and acidification of methyl $\alpha$-D-glucoside, D-xylose, rhamnose and ribose. This API-Listeria profile (7630) did not fit any known profile in the profile database provided by the manufacturer. Based on results of the API $50 \mathrm{CH}$ system, acid was produced from glycerol, erythritol, ribose, D-xylose, adonitol, galactose, D-glucose, D-fructose, D-mannose, Lsorbose, rhamnose, dulcitol, inositol, mannitol, sorbitol, methyl $\alpha$-D-glucoside, $N$-acetylglucosamine, amygdalin, arbutin, salicin, aesculin, cellobiose, maltose, lactose, melibiose, soluble starch, trehalose, D-raffinose, glycogen and $\beta$ gentiobiose. Acid was not produced from D-arabinose, Larabinose, L-xylose, methyl $\beta$-xyloside, methyl $\alpha$-D-manno-

Table 1. Characteristics that distinguish strain CIP $109804^{\top}$ from closely related species of the genus Listeria

Species: 1, L. rocourtiae sp. nov.; 2, L. monocytogenes, 3, L. innocua; 4, L. seeligeri; 5 , L. ivanovii subsp. londoniensis; 6, L. ivanovii subsp. ivanovii; $7, L$. welshimeri; 8. L. grayi. All species are aesculin hydrolysis positive. + , Positive reaction; $(+)$, weak or delayed positive reaction; - , negative reaction; $\mathrm{V}$, variable reaction. Data from this study and Seeliger \& Jones (1986).

\begin{tabular}{|lllllllll|}
\hline Characteristic & $\mathbf{1}$ & $\mathbf{2}$ & $\mathbf{3}$ & $\mathbf{4}$ & $\mathbf{5}$ & $\mathbf{6}$ & $\mathbf{7}$ & $\mathbf{8}$ \\
\hline$\beta$-haemolysis & - & + & - & + & + & + & - & - \\
CAMP test & & & & & & & & \\
$\quad$ S. aureus & - & + & - & $(+)$ & - & - & - & - \\
$\quad$ R. equi & - & - & - & - & + & + & - & - \\
Arylamidase & - & - & + & + & $\mathrm{V}$ & $\mathrm{V}$ & $\mathrm{V}$ & + \\
PIPLC & - & + & - & - & + & + & - & - \\
$\alpha$-Mannosidase & + & + & + & - & - & - & + & $\mathrm{V}$ \\
Fermentation of: & & & & & & & & \\
$\quad$ Mannitol & + & - & - & - & - & - & - & + \\
$\quad$ D-Arabitol & - & + & + & + & + & + & + & + \\
$\quad$ D-Xylose & + & - & - & + & + & + & + & - \\
$\quad$ Rhamnose & + & + & $\mathrm{V}$ & - & - & - & $\mathrm{V}$ & - \\
$\quad$ Methyl $\alpha$-D-glucoside & + & + & + & + & + & + & + & $\mathrm{V}$ \\
$\quad$ Ribose & + & - & - & - & - & + & - & + \\
$\quad$ Glucose-1-phosphate & - & - & - & - & $\mathrm{V}$ & $\mathrm{V}$ & - & - \\
$\quad$ D-Tagatose & - & - & - & - & - & - & + & - \\
\hline
\end{tabular}

side, sucrose, inulin, melezitose, xylitol, L-fucose, D-turanose, D-lyxose, D-tagatose, D-fucose, D-arabitol, gluconate, 2ketogluconate and 5-ketogluconate. On the RAPID' L.mono medium, colonies were white surrounded by a yellow halo, indicating that this strain was PIPLC negative and xylosepositive. This isolate did not grow on the chromogenic medium ALOA (Leclercq, 2004). The multiplex PCR (Doumith et al., 2004a) was negative. This strain was not agglutinated by sera I to XV targeting known somatic antigens, and did not react with sera directed against flagellar antigens $\mathrm{A}, \mathrm{AB}, \mathrm{C}, \mathrm{D}$ and $\mathrm{E}$. Thus, this strain had no specific serotype or PCR group described for the genus Listeria to date.

The rrs gene sequence determined consisted of a continuous stretch of $1539 \mathrm{nt}$. A comparison of the rrs gene sequence of strain CIP $109804^{\mathrm{T}}$ with that of other members of the genus Listeria is shown in Table 2 (1467 nt compared). Per cent rrs gene sequence similarities between $L$. rocourtiae sp. nov. and other species were 95.84 (L. monocytogenes, L. welshimeri), 95.64 (L. innocua, L. grayi), 95.57 (L. ivanovii), 94.96 (L. seeligeri), 91.89 (Brochothrix thermosphacta) and 91.68 (Brochothrix campestris). Jukes-Cantor distance values ranged from 0.042 to 0.046 between strain CIP $109804^{\mathrm{T}}$ and all other type strains of the genus Listeria. These values are comparable with those between L. grayi and other species of the genus Listeria (0.037 to 0.043). The tree in Fig. 1 shows the phylogenetic relationships of strain CIP $109804^{\mathrm{T}}$ and other members of the genus Listeria based on the rrs gene sequence (Stackebrandt \& Goebel, 1994). This tree clearly shows that the newly characterized strain CIP $109804^{\mathrm{T}}$ represents a distinct species and belongs to the genus Listeria as long as this genus includes $L$. grayi.

The gene content of strain CIP $109804^{\mathrm{T}}$ was surveyed by using a Listeria biodiversity DNA array. When compared with 27 strains representative of the different serogroups of L. monocytogenes and 13 isolates representing all other species of the genus Listeria (Supplementary Table S1, available in IJSEM online), strain CIP $109804^{\mathrm{T}}$ clustered within the genus Listeria and was closely related to $L$. ivanovii subsp. ivanovii (Supplementary Fig. S1). The clustering derived from the biodiversity DNA array should not be taken as a phylogenetic tree since genes on the array represented only L. monocytogenes and L. innocua. It shows that $L$. rocourtiae sp. nov. is not excluded at the periphery of the tree and shares some genes with $L$. ivanovii. The number of reacting probes per species were as follows: $L$. monocytogenes (263-513, mean 403), L. innocua (219-311, mean 262), L. welshimeri (162-206, mean 184), L. seeligeri (31-119, mean 75), L. ivanovii (87-235, mean 146), L. grayi (322) and L. rocourtiae sp. nov. (189). Typical Listeria genes, such as those known to encode 11 LPxTG anchorcontaining surface proteins, were detected in strain CIP $109804^{\mathrm{T}}$, further supporting that this strain should be classified in the genus Listeria. Furthermore, many transcriptional regulators and teichoic acid biosynthesis genes present in other Listeria genomes were identified. 
Table 2. Jukes-Cantor distance for a $1467 \mathrm{nt}$ region of the $r$ s gene of strain CIP $109804^{\top}$ and some representatives of the genera Listeria and Brochothrix

1, Listeria monocytogenes NCTC $10357^{\mathrm{T}}$ (accession no. X56153.1); 2, Listeria innocua NCTC $11288^{\mathrm{T}}$ (X56152.1); 3, Listeria welshimeri NCTC $11857^{\mathrm{T}}$ (X56149.1); 4, Listeria seeligeri NCTC $11856^{\mathrm{T}}$ (X56148.1); 5, Listeria ivanovii subsp. ivanovii $\mathrm{NCTC}_{11846^{\mathrm{T}}}$ (X56151.1); 6, Listeria grayi CIP $68.18^{\mathrm{T}}$ (X56150.1); 7, Brochothrix thermosphacta NCDO $1676^{\mathrm{T}}$ (X56155.1); 8, Brochothrix campestris ATCC $43754^{\mathrm{T}}$ (X56156.1).

\begin{tabular}{|c|c|c|c|c|c|c|c|c|}
\hline Strain & 1 & 2 & 3 & 4 & 5 & 6 & 7 & 8 \\
\hline Listeria monocytogenes NCTC $10357^{\mathrm{T}}$ & & 0.005 & 0.010 & 0.008 & 0.015 & 0.043 & 0.083 & 0.080 \\
\hline Listeria welshimeri NCTC $11857^{\mathrm{T}}$ & & & & 0.006 & 0.010 & 0.037 & 0.086 & 0.081 \\
\hline Listeria seeligeri NCTC $11856^{\mathrm{T}}$ & & & & & 0.008 & 0.037 & 0.078 & 0.074 \\
\hline Listeria ivanovii subsp. ivanovii NCTC $11846^{\mathrm{T}}$ & & & & & & 0.037 & 0.083 & 0.079 \\
\hline
\end{tabular}

Strain CIP $109804^{\mathrm{T}}$ did not form plaques in HT-29 cell culture and was unable to colonize the spleens of Swiss mice 3 days after subcutaneous inoculation. Strain CIP $109804^{\mathrm{T}}$ should be classified within the avirulent group of species of the genus Listeria, exhibiting no virulence according to the Roche et al. (2001) classification.

Strain CIP $109804^{\mathrm{T}}$ was naturally sensitive or showed intermediate sensitivity to carbapenems, rifampicin, macrolides, lincosamides, linezolid, glycopeptides, gentamicin, ciprofloxacin, levofloxacin, moxifloxacin, fusidic acid and chloramphenicol. However, strain CIP $109804^{\mathrm{T}}$ was resistant to cephalosporins $\left(>32 \mathrm{mg} \mathrm{l}^{-1}\right)$, sulfamethoxazole $\left(0.023 \mathrm{mg}^{-1}\right)$ and nalidixic acid $(>256 \mathrm{mg}$ $1^{-1}$ ), similar to other species of the genus Listeria (Troxler et al., 2000), and resistant to tetracyclines $\left(1.5 \mathrm{mg} \mathrm{l}^{-1}\right)$, trimethoprim $\left(0.032 \mathrm{mg} \mathrm{l}^{-1}\right)$, fosfomycin $\left(96 \mathrm{mg} \mathrm{l}^{-1}\right)$,

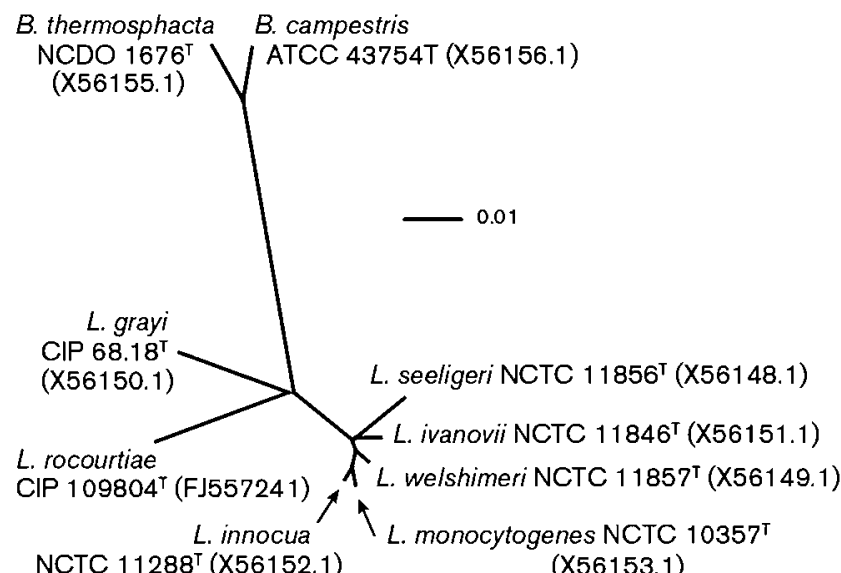

Fig. 1. Unrooted tree showing the phylogenetic relationship of strain CIP $109804^{\top}$ and species of the genera Listeria and Brochothrix (the closest genus), based on a distance matrix of $r$ rs gene sequences (1467 nt). The tree is based on an analysis of a continuous stretch of approximately 1467 nt. Bar, 1 substitution per $100 \mathrm{nt}$. kanamycin $\left(>4 \mathrm{mg} \mathrm{l}^{-1}\right)$ and streptomycin $\left(8 \mathrm{mg} \mathrm{l}^{-1}\right)$. In vitro resistance to $\beta$-lactams was unexpected, with minimal inhibitory concentrations to penicillin, ampicillin and amoxycillin $>256 \mathrm{mg} \mathrm{l}^{-1}$.

Thus, on the basis of the molecular findings described above as well as the phenotypic distinctiveness of strain CIP $109804^{\mathrm{T}}$, we propose that this strain should be classified as a member of a novel species, Listeria rocourtiae sp. nov.

\section{Description of Listeria rocourtiae sp. nov.}

Listeria rocourtiae (ro.cour'ti.ae. N.L. fem. gen. n. rocourtiae named in honour of Jocelyne Rocourt, French bacteriologist, whose work had a major impact on the taxonomy of the genus Listeria).

Cells are regular, short rods, $0.4-0.5 \mu \mathrm{m}$ in diameter and $1-2 \mu \mathrm{m}$ in length with rounded ends. Gram-stain-positive. Not acid-fast. Capsule not formed. Does not form spores. Motile when cultured at 4 to $30{ }^{\circ} \mathrm{C}$. Aerobic and facultatively anaerobic. Colonies appear bluish grey by normal illumination and a characteristic blue-green sheen is produced by obliquely transmitted light. After $48 \mathrm{~h}$ of incubation on trypto-casein-soy agar at $30{ }^{\circ} \mathrm{C}$, colonies are $0.5-1.0 \mathrm{~mm}$ in diameter, round, translucent and low convex with a finely textured surface and entire margin. Acid is produced from glycerol, erythritol, ribose, D-xylose, adonitol, galactose, D-glucose, D-fructose, D-mannose, Lsorbose, rhamnose, dulcitol, inositol, mannitol, sorbitol, methyl $\alpha$-D-glucoside, $N$-acetylglucosamine, amygdalin, arbutin, salicin, cellobiose, maltose, lactose, melibiose, soluble starch, trehalose, D-raffinose, glycogen and $\beta$ gentiobiose. Acid is not produced from D-arabinose, $\mathrm{L}-$ arabinose, L-xylose, methyl $\beta$-xyloside, methyl $\alpha$-D-mannoside, sucrose, inulin, melezitose, xylitol, L-fucose, Dturanose, D-lyxose, D-tagatose, D-fucose, D-arabitol, gluconate, 2-ketogluconate or 5-ketogluconate. The type strain is non-haemolytic, CAMP-test negative and avirulent.

The type strain is strain CIP $109804^{\mathrm{T}}$ (=DSM $22097^{\mathrm{T}}$ $=$ Allerberger $700284 / 02^{\mathrm{T}}$ ) and was isolated from pre-cut 
lettuce in Salzburg, Austria, in 2002. The lettuce was grown and processed in Siezenheim, a village near Salzburg.

\section{Acknowledgements}

We thank M. Gomard for expert technical support. This work was supported by grants of the European Commission (GENE project QLK2-200-01404), by the Austrian Jubilee Fund (no. 9292) and the Institut Pasteur.

\section{References}

Anonymous (2006). Communiqué 2006 du comité de l'antibiogramme. Société Française de Microbiologie, Paris. http://www.sfm. asso.fr

Audurier, A., Pardon, P., Marly, J., Lantier, F. \& Loulergue, J. (1981). Mesure de la virulence chez la souris de différentes bactéries appartenant au genre Listeria. Ann Immunol (Paris) 132D, 191-200.

Bille, J., Catimel, B., Bannerman, E., Jacquet, C., Yersin, M. N., Caniaux, I., Monget, D. \& Rocourt, J. (1992). API Listeria, a new and promising one-day system to identify Listeria isolates. Appl Environ Microbiol 58, 1857-1860.

Böttger, E. C. (1989). Rapid determination of bacterial ribosomal RNA sequences by direct sequencing of enzymatically amplified DNA. FEMS Microbiol Lett 53, 171-176.

Christie, R., Atkins, N. E. \& Munch-Petersen, E. (1944). A note on a lytic phenomenon shown by group B streptococci. Aust J Exp Biol Med Sci 22, 197-200.

Doumith, M., Buchrieser, C., Glaser, P., Jacquet, C. \& Martin, P. (2004a). Differentiation of the major Listeria monocytogenes serovars by multiplex PCR. J Clin Microbiol 42, 3819-3822.

Doumith, M., Cazalet, C., Simoes, N., Frangeul, L., Jacquet, C., Kunst, F., Martin, P., Cossart, P., Glaser, P. \& Buchrieser, C. (2004b). New aspects regarding evolution and virulence of Listeria monocytogenes revealed by comparative genomics and DNA arrays. Infect Immun 72, 1072-1083.

Dysvik, B. \& Jonassen, I. (2001). J-Express: exploring gene expression data using Java. Bioinformatics 17, 369-370.

Fogh, J. \& Trempe, G. (1975). New human tumor cell lines. In Human Tumor Cells In Vitro, pp. 115-141. Edited by J. Fogh. New York: Plenum Press.

Hong, E., Doumith, M., Duperrier, S., Giovannacci, I., Morvan, A., Glaser, P., Buchrieser, C., Jacquet, C. \& Martin, P. (2007). Genetic diversity of Listeria monocytogenes recovered from infected persons and pork, seafood and dairy products on retail sale in France during 2000 and 2001. Int J Food Microbiol 114, 187-194.

Jukes, T. H. \& Cantor, C. R. (1969). Evolution of protein molecules. In Mammalian Protein Metabolism, vol. 3, pp. 21-132. Edited by $\mathrm{H}$. N. Munro. New York: Academic Press.

Leclercq, A. (2004). Atypical colonial morphology and low recoveries of Listeria monocytogenes strains on Oxford, PALCAM, Rapid' L.mono and ALOA solid media. J Microbiol Methods 57, 251-258.

Roche, S. M., Velge, P., Bottreau, E., Durier, C., Marquet-van der Mee, N. \& Pardon, P. (2001). Assessment of the virulence of Listeria monocytogenes: agreement between a plaque-forming assay with HT29 cells and infection of immunocompetent mice. Int J Food Microbiol 68, 33-44.

Rocourt, J. \& Buchrieser, C. (2007). The genus Listeria and Listeria monocytogenes: phylogenetic position, taxonomy, and identification. In Listeria, Listeriosis, and Food Safety, 3rd edn, pp. 1-20. Edited by E. T. Ryser \& E. H. Marth. Boca Raton, FL: CRC Press.

Rocourt, J., Grimont, F., Grimont, P. A. D. \& Seeliger, H. P. R. (1982). DNA relatedness among serovars of Listeria monocytogenes sensu lato. Curr Microbiol 7, 383-388.

Saitou, N. \& Nei, M. (1987). The neighbor-joining method: a new method for reconstructing phylogenetic trees. Mol Biol Evol 4, 406425.

Seeliger, H. P. R. \& Höhne, K. (1979). Serotyping of Listeria monocytogenes and related species. Methods Microbiol 13, 31-49.

Seeliger, H. P. R. \& Jones, D. (1986). Genus Listeria pirie 1940, $383^{\mathrm{AL}}$. In Bergey's Manual of Systematic Bacteriology, vol. 2, pp. 1235-1245. Edited by P. H. A. Sneath, N. S. Mair, M. E. Sharpe \& J. G. Holt. Baltimore: Williams \& Wilkins.

Stackebrandt, E. \& Goebel, B. M. (1994). Taxonomic note: a place for DNA-DNA reassociation and 16S rRNA sequence analysis in the present species definition in bacteriology. Int J Syst Bacteriol 44, 846849.

Thompson, J. D., Gibson, T. J., Plewniak, F., Jeanmougin, F. \& Higgins, D. G. (1997). The CLUSTAL_X windows interface: flexible strategies for multiple sequence alignment aided by quality analysis tools. Nucleic Acids Res 25, 4876-4882.

Troxler, R., von Graevenitz, A., Funke, G., Wiedemann, B. \& Stock, I. (2000). Natural antibiotic susceptibility of Listeria species: L. grayi, L. innocua, L. ivanovii, L. monocytogenes, L. seeligeri and L. welshimeri strains. Clin Microbiol Infect 6, 525-535.

Volokhov, D. V., Duperrier, S., Neverov, A. A., George, J., Buchrieser, C. \& Hitchins, A. D. (2007). The presence of the internalin gene in natural atypically haemolytic Listeria innocua strains suggests descent from $L$. monocytogenes. Appl Environ Microbiol 73, 1928-1939. 